\title{
Experiencia de Trabajo Social en atención a pacientes con VIH-SIDA que requieren tratamiento específico en una unidad médica pública, Ecuador
}

\section{Experience of Social Work in the care of patients with HIV-AIDS requiring specific treatment in a public medical unit, Ecuador}

\author{
DOI: $10.46932 / \operatorname{sjdv} 3 n 1-084$
}

Received in: Jan 30st, 2021

Accepted in: Feb 1th, 2022

\author{
Lcda. Marylin González Cuichán \\ Fundación Nakuna / Quito - Ecuador \\ E-mail: lizethcuichan18@gmail.com
}

\author{
Dra. Soraya del Pilar Carranco Madrid Ph.D \\ Universidad Central del Ecuador / Quito - Ecuador \\ E-mail: spilarcm@hotmail.com \\ MSc. Jorge Antonio Piedra Rosales \\ Universidad Central del Ecuador / Quito - Ecuador \\ E-mail: japiedra@uce.edu.ec
}

\begin{abstract}
RESUMEN
El presente artículo científico buscar transmitir con una perspectiva de derechos, las experiencias de Trabajo Social en atención a pacientes con VIH - SIDA que requieren tratamiento específico en una Unidad Médica Pública de Ecuador. Ejercicio profesional que como parte del equipo multidisciplinario de salud interviene en la problemática que aqueja a este tipo de pacientes, para que accedan a su tratamiento antirretroviral; para lo cual aplica métodos, técnicas e instrumentos propios del ejercicio profesional del Trabajo Social, que facilitaron el abordaje de la realidad de las personas seropositivas y la importancia de acceder a un tratamiento específico, para mantener un buen estado de salud, que les permita llevar una vida con dignidad. Desde Trabajo Social es importante la intervención con una perspectiva comprometida, social, holística, humanística, de derechos, que promueva el bienestar de un importante sector de la población que por su enfermedad, sufre de discriminación y aún es invisibilizada por la sociedad y por el Estado.
\end{abstract}

Palabras clave: Intervención Profesional , Trabajo Social, Trabajo Social En Salud , VIH-SIDA , Tratamiento Antirretroviral.

\section{ABSTRACT}

This scientific article seeks to transmit, with a rights perspective, the experiences of Social Work in the care of patients with HIV - AIDS who require specific treatment in a Public Medical Unit in Ecuador. Professional exercise that, as part of the multidisciplinary health team, intervenes in the problems that afflict this type of patient, so that they can access their antiretroviral treatment; for which it applies methods, techniques and instruments typical of the professional practice of Social Work, which facilitated the approach to the reality of seropositive people and the importance of accessing specific treatment, to maintain a good state of health, which allows them to lead a life with dignity. From Social Work, it is important to intervene with a committed, social, holistic, humanistic, rights perspective, which promotes 
the well-being of an important sector of the population that, due to their illness, suffers from discrimination and is still made invisible by society and by the Condition.

Keywords: Professional Intervention, Social Work, Social Work In Health, HIV-AIDS , Antiretroviral Treatment.

\section{INTRODUCCIÓN}

El presente estudio investigativo, dice relación a la intervención del Trabajador Social y la labor que realiza con los pacientes que tienen VIH SIDA. La aplicación del conocimiento teórico a la realidad puede ser vista como un desafío y una oportunidad para desarrollar la capacidad de respuesta y de toma de decisiones ante situaciones complejas, las mismas que supongan algún cambio en la realidad de las persona a las que se atienda; para lograrlo es preciso desarrollar y potencializar las habilidades necesarias que permitan a los profesionales llevar a cabo una atención eficiente, eficaz y oportuna, con calidad y calidez para promover el mejoramiento de su calidad de vida. Para ello es necesaria la aplicación de técnicas e instrumentos científicos propios de Trabajo Social (ficha 038, fichas socioeconómicas, informes sociales, diarios de campo, registro diario de atención, hojas de ruta, etc) para la recolección de datos e información ordenada de las personas que son sujetos de nuestra intervención.

De ahí la importancia de investigar este tema en pacientes considerados vulnerables en la sociedad. Este trabajo analiza la problemática del grupo de personas infectadas con VIH, las mismas que a través del tiempo viven situaciones que las han relegado y discriminado por su condición, debido al desconocimiento de la enfermedad y sus formas de tratamiento, pues continuamente se la relaciona con la muerte y otros problemas sociales que llevan a la estigmatización de estas personas, ya que esta enfermedad no está definida por alguna característica en especial, pues cualquier persona puede infectarse sin discriminación de sexo, raza, edad, preferencia sexual o algún factor biológico que se pueda considerar como indicador de vulnerabilidad ante esta infección.

El Trabajador Social en el ámbito de la salud desempeña un rol importante pues al estar en contacto con distintas realidades sociales y presenciar problemáticas colectivas e individuales, le brinda la oportunidad de generar un análisis crítico acerca de las mismas y de los factores que propician dichas condiciones, que afectan tanto al individuo como a su entorno por lo que la atención integral de estas personas requiere estrictamente de del conjunto de acciones abordadas por un equipo integral que necesariamente necesita del ejercicio de Trabajo Social dentro del proceso de abordaje de la problemática o de la enfermedad.

Según Barranco (2004) "La intervención del Trabajo Social es entendida como la acción organizada y desarrollada por los Trabajadores Sociales con las personas, grupos y comunidades, y sus 
objetivos están orientados a superar los obstáculos que impiden avanzar en el desarrollo humano y en mejora de la calidad de vida..." (Barranco, 2004).

Así mismo, según palabras de Ávila - Cedillo (2020), las funciones principales del Trabajador Social en Salud, son:

\begin{tabular}{|c|c|}
\hline ROLES & ACCIONES \\
\hline 1. Investigador & $\begin{array}{l}\text { Descubrirá la realidad social concreta de grupos e individuos con alguna } \\
\text { enfermedad específica, con el fin de promover un desarrollo óptimo y aporte de } \\
\text { nuevos conocimientos a la medicina, mediante la sistematización o publicación de } \\
\text { la investigación. }\end{array}$ \\
\hline 2. Defensor & $\begin{array}{l}\text { Velará por los derechos humanos y la dignidad de las personas, principalmente } \\
\text { en su estado de vulnerabilidad ante su situación de salud. }\end{array}$ \\
\hline 3. Asesor-Informador & $\begin{array}{l}\text { Asesorará y orientará en los distintos procedimientos de los trámites de los usuarios } \\
\text { en las instituciones de salud. }\end{array}$ \\
\hline 4. Comunicador & $\begin{array}{l}\text { Tendrá una comunicación asertiva, amable y cordial con los usuarios y su } \\
\text { equipo de intervención. }\end{array}$ \\
\hline 5. Experto grupal & $\begin{array}{l}\text { Coordinará grupos de psicoeducación, con el fin de que los pacientes y familiares } \\
\text { generen un proceso de reflexión-catarsis y socialicen sus padecimientos- } \\
\text { sufrimientos. }\end{array}$ \\
\hline 6. Promotor & $\begin{array}{l}\text { Promoverá estilos saludables de vida e información sobre prevención de diversas } \\
\text { enfermedades. }\end{array}$ \\
\hline 7. Estratega & $\begin{array}{l}\text { Proyectará influencia positiva hacia el equipo multidisciplinario para generar } \\
\text { cambios en favor de los pacientes de los servicios de salud, por medio de la } \\
\text { promoción de proyectos innovadores }\end{array}$ \\
\hline 8. Observador & $\begin{array}{l}\text { Será muy diligente con toda la información que reciba, para analizarla y } \\
\text { tomar decisiones correctas y oportunas. }\end{array}$ \\
\hline 9. Lider-Coordinador & $\begin{array}{l}\text { Tendrá la capacidad de gerenciar y dirigir equipos de trabajo y proyectos } \\
\text { institucionales para posicionar la labor del trabajador social }\end{array}$ \\
\hline 10. Agente catalizador & $\begin{array}{l}\text { Concientiza las potencialidades y debilidades de la persona incentivando } \\
\text { procesos de re-significación social y resiliencia }\end{array}$ \\
\hline
\end{tabular}
Fuente: Ávila - Cedillo , (2020, p. 6)

En este mismo sentido, según la opinión de (González, De León, 2015), el trabajo social debe estar enfocado en el cuidado de la salud desde un punto de vista integral, es decir todas las acciones que se tomen a favor de los pacientes deben estar directamente relacionados con las decisiones que se tomen desde la institución, lo que conlleva un trabajo interdisciplinario donde el principal protagonista es el trabajador social, quien será el encargado de coordinar todos los aspectos que involucran un cuidado integral. Como se citó en (Vásconez-Alvarado \& Galarza Schoenfeld, 2021, p. 1298) 
El estudio realizado en un centro médico público de Ecuador, tiene como finalidad el brindar una pauta para llevar a cabo una atención adecuada y de calidad a los pacientes, promoviendo la inclusión en todos sus aspectos y respetando la diversidad de grupos poblacionales. Una muestra de esto es la adecuación de infraestructura a este tipo de instituciones la misma debe atender a las distintas necesidades que presentan las personas, estos antecedentes permiten que los futuros y futuras profesionales tengan bases tanto teóricas como prácticas de la variedad de realidades que se presentan en sus formas más básicas hasta las más complejas.

El VIH según la OMS se define como "Virus de Inmunodeficiencia Humana", que infecta a las células del sistema inmunitario, alterando o anulando su función. Así también esta infección produce un deterioro progresivo del sistema inmunitario, con la consiguiente inmunodeficiencia, es decir que deja de cumplir su función de lucha contra las infecciones y enfermedades. (Organización Mundial de la Salud, s.f.)

El VIH y el SIDA mantienen una diferencia, pues estos términos se tratan de dos condiciones distintas; el Ministerio de Salud dice que el SIDA es la condición a la que se llega cuando el virus del VIH está en sus niveles más altos, es decir no ha sido tratado y por lo tanto la reproducción del mismo dentro del cuerpo y el organismo de la persona infectada se produjo en mayor cantidad y rapidez al no ser combatido con el medicamento y el tratamiento antirretroviral que reduzca y ralentice su progreso, el mismo tratamiento se encargará de impedir que el virus se reproduzca y se propague debilitando el sistema inmune de la persona. (Ministerio de Salud Pública, 2002)

El VIH al ingresar al organismo de una persona puede tardar meses y hasta años en presentar síntomas, entre las principales formas de contagio están; el contacto directo con secreciones vaginales, semen, el uso de jeringas compartidas, relaciones sexuales sin protección, y por la leche materna de una madre portadora hacia su bebé, este virus genera la disminución de las defensas del cuerpo, debilitando el sistema inmunológico y consecuentemente generando mayor vulnerabilidad para adquirir enfermedades con mayor facilidad.

La realización de este trabajo de investigación tiene como característica principal el conocer el trabajo que realizan las profesionales de Trabajo Social desde la perspectiva de la defensa y el aseguramiento del ejercicio pleno de los derechos de las personas, principalmente de la vida digna y el acceso una atención de salud, ofreciendo una visión más amplia de la forma en la que los y las profesionales se desenvuelven en el ámbito de la salud con las personas que viven con VIH y la obtención de un lugar para que estas reciban el tratamiento antirretroviral necesario para que su salud no se vea afectada a corto plazo. 
El abordaje realizado desde una perspectiva de derechos, procura despertar el interés académico y profesional como Trabajadores, as Sociales y el rol que cumplimos en el contexto social, promoviendo la salud de las personas, en este caso el de las personas que viven con VIH y las situaciones que se desarrollan en su vida cotidiana así como de los determinantes de salud que influyen a la infección; si por el contrario este tipo de temas no se tratan se seguirán invisibilizando, restando la importancia que supone este problema de salud en la sociedad y de un sistema de salud que no cubre las necesidades más básicas que este grupo requiere respecto al tratamiento que necesitan para su enfermedad.

Precisamente, una de las limitantes es la falta de recursos en el sistema nacional de salud que genera desabastecimiento de medicamentos y que aún más se ha visto afectado por la pandemia que vivimos a nivel mundial, y que ha supuesto una prioridad y un punto de atención porque se resume en el poco interés que se le da a las demás condiciones de salud que existen en la sociedad las mismas que requieren de una atención continua, lo que genera un interés de conocer porque este grupo poblacional sigue viviendo situaciones complejas tanto dentro del ámbito social y del ámbito de las salud principalmente al momento de conseguir el medicamento para su tratamiento antirretroviral.

Además de un necesario análisis del comportamiento de las personas respecto a la enfermedad, principalmente de quienes la padecen como de las personas que se encuentran y su entorno más próximo, la cultura misma que se presenta alejada a una de las realidades latentes pero invisibilizadas en materia de salud; es indispensable el fomento del debate de este tema, de esta población y la adquisición de conocimiento global acerca de esta infección para que se vayan desmintiendo los mitos y creencias que se han construido entorno a la misma.

En este sentido, Trabajo Social promueve la capacidad que tienen las personas de análisis respecto de su enfermedad y de llegar a encontrar soluciones y respuestas positivas al desenvolvimiento que tienen dentro de la sociedad respecto a su condición de vida, tratándose de las personas con VIH como las personas que no lo padecen pero que se encuentran inmersos en la condición y el entorno de vida de este grupo considerado vulnerable para sociedad.

El Trabajo Social aplica métodos, técnicas e instrumentos en forma metodológica, ordenada y estructurada, permitiéndole desarrollar procesos efectivos y oportunos, en beneficio de la población con la que esté trabajando, cumpliendo con pasos correlacionados unos con otros, para que estos nos ayuden a conocer, diagnosticar, establecer y posteriormente a ejecutar planes que busquen resultados que se deben plantear al inicio de la intervención.

El presente estudio, utiliza el método de caso para establecer una atención más personalizada y directa con el paciente, contribuyendo a su bienestar físico y emocional. 
Es importante, analizar y visibilizar la intervención de Trabajo Social en la atención a las personas con VIH, para la obtención del tratamiento antirretroviral que les permita llevar una vida lo más normal posible, y a su vez generar alternativas de respuesta a la forma en la que dichas personas son vistas dentro de la sociedad, promoviendo la eliminación de todas las formas de discriminación y de violencia a las que se han visto expuestas, también se cree que es trascendental que los pacientes seropositivos se sientan con la seguridad plena de ser visibles y llegar a alimentar su conciencia acerca de la nueva condición de su vida para que cree hábitos de cuidado y de compromiso a seguir estrictamente su tratamiento.

Otro de los propósitos que tiene esta investigación es aportar al conocimiento e interés de estudiar estos temas de salud y ampliar la visión de las y los Trabajadores Sociales para que se direccionen a los demás grupos vulnerables de la población, como es el caso de las personas que son portadores de VIHSIDA, dando con ello un viraje de calidad en la intervención a estos casos, con una perspectiva humana, de derechos.

Las principales limitaciones presentadas en este trabajo, es la escasa bibliografía acerca de este tema, para tener una visión más amplia de las realidades que se dan entorno a las personas que son diagnosticadas con VIH en los centros médicos públicos. Otra de las limitaciones es la falta de decisión del Estado para abastecer de recursos a un sistema de salud que requiere brindar y satisfacer las necesidades a los problemas de salud que presentan las personas, y que principalmente no pone en práctica la importancia de dirigir los recursos suficientes para el contrato de compra de medicamentos y de inversión en infraestructura para que se brinde la garantía de los derechos fundamentales de los seres humanos, particularmente de quienes padecen VIH - SIDA.

\section{METODOLOGÍA Y METODOS}

Asumimos la definición de metodología de, Ander Egg (1985), que describe a la "Metodología como la ciencia o teoría sobre los métodos para el conocimiento científico de las realidades sociales y para la transformación de la misma. Comenzó a adquirir importancia desde comienzos de la edad moderna, cuando Bacon, Galileo y luego Descartes, plantearon la cuestión "del mejor camino para llegar a un conocimiento efectivo, y, a la vez, riguroso de la naturaleza”. Citado en Gordillo, (2007, p. 6)

Sin lugar a dudas, este trabajo tiene un enfoque metodológico de corte cualitativo - descriptivo, a través de la combinación de dos técnicas usadas por los profesionales de Trabajo Social, fundamentalmente la observación y la entrevista, con el fin de recabar información partiendo de la opinión u opiniones de las personas a las que se dirigen las acciones del profesional para atender una situación en particular, este es el caso de la población que vive con VIH y la importancia para estos de conseguir un tratamiento antirretroviral a través del acompañamiento de un equipo capacitado para llevar su caso. 
Se consideró importante asumir y aplicar esta metodología, pues "La investigación cualitativa posee un enfoque multimetódico en el que se incluye un acercamiento interpretativo y naturalista al sujeto de estudio, esto significa que el investigador cualitativo estudia las cosas en sus ambientes naturales, pretendiendo darle sentido o interpretar los fenómenos en base a los significados que las personas les otorgan". (Alvarez y otros, s.f.)

Se considera que dicho método se ha interesado por entender el aspecto EMIC de los usuarios, los puntos de vista individuales de los sujetos que son parte de la atención. A partir de esta perspectiva se construye un acercamiento más directo con las personas, aunque existe también la posibilidad de que los pacientes generen ciertas limitaciones al momento de dar información personal por lo que omitirían aspectos y detalles que pueden ser importantes, a más de conocer al paciente este enfoque permite ampliar la mirada a los usuarios externos como internos que formen parte del caso que se esté atendiendo además de comprender la perspectiva del conjunto de miembros del equipo multidisciplinario como médicos, personal de apoyo, ya que de estas dos aristas se desprenden ciertos valores, creencias, opiniones, percepciones, y comportamientos que se direccionan al paciente, su contexto y por ende a la enfermedad que requiere de atención.

Consideramos importante destacar al método de caso, como el camino eficaz a ser utilizado en esta investigación para la consecución del objetivo que es conocer la intervención del Trabajo Social con las personas portadoras de $\mathrm{VIH}$, este método nos permite de manera ordenada conseguir los resultados que esperamos.

"El Trabajo Social de casos es un servicio personal proporcionado por Trabajadores preparados hacia individuos que requieren ayuda especializada a fin de resolver algún problema material, emocional o de carácter. Esta es una actividad disciplinada que requiere una plena apreciación de las necesidades que presente el cliente en el lugar que ocupa en su familia o en la comunidad..." (Davison, 1973) citado en (Barreto Acosta et al., 2003, p. 114). Siendo el ser humano el eje principal y objeto de estudio e intervencion de Trabajo Social, poniendo especial atencion a sus necesidades y las formas en las que pueden satisfacer las demandas sociales, suponen el punto de inicio de las acciones profesionales.

Este método le permite al Trabajador Social resolver en ese momento el problema que se presente con las personas, pues eso contribuye a generar el menor impacto posible en su salud mental, emocional y física el momento en el que recibe un diagnóstico de carga positiva de virus en su organismo, a partir de este momento el paciente está en la obligación de tomar una decisión sobre cómo quiere actuar frente a su nueva condición, esto acompañado de un equipo profesional que dé seguimiento a su caso y el compromiso que se genere para tomar y seguir con el tratamiento necesario para cuidar de su estado de salud. 
La elección de esta población (PVVIH) de un centro médico público de Ecuador, fue motivada por la necesidad de tratar temas que generan algún tipo de interés, y que no son muy comúnmente cuestionados o debatidos en la sociedad y en este caso en un sistema de salud que aún mantiene deficiencias respecto de su tratamiento y atención, es por esto que la población de la que se habla en este trabajo es una de las tantas que son atendidas a diario en los centros médicos públicos, y de los cuales muy pocas veces se trata, lo que lleva a un trabajo más enfocado, en este caso a las personas que viven con VIH, de quienes históricamente la sociedad ha mantenido, replicada una visión y criterio equivocados, estigmatizados, estereotipados sobre la enfermedad, con argumentos y denominaciones estigmatizadoras que se van generalizando pues esto supone la reproducción de construcciones culturales de la sociedad alrededor de las distintas características de los diversos grupos que conviven dentro de la misma, los estigmas se forman para ir en contra, apartar o señalar a un grupo en particular que se considere como diferente, o que de cierta manera amenace a lo que se cree normal, o la convencionalidad en la que se desenvuelven las demás personas y así creando distintivos que se utilizan para desacreditarlos. (Capella et al., 2018)

El centro médico público en el que se desarrolló este estudio tiene como fin brindar una adecuada atención con calidad y la seguridad del ejercicio de su derecho a la salud, es importante destacar que un centro médico debe ser inclusivo lo que significa el estar adecuado tanto con profesionales capacitados como contar con una infraestructura adecuada que atienda a las necesidades físicas, biológicas de las personas.

Para trabajar con la población mencionada, se utilizaron técnicas e instrumentos propios del Trabajo Social como el diario de campo, fichas socioeconómicas o la ficha 038 , los informes sociales, el parte diario o registro de atención a pacientes, solicitudes de pruebas para el VIH, informes mensuales de actividades realizadas, guías de atención a pacientes con VIH, etc., estas que suponen un conjunto de procedimientos y recursos que se ponen en práctica para obtener un resultado o información pertinente a cerca de la persona con la que se está trabajando, estos instrumentos son la base para la aplicación de las técnicas consideradas como "un conjunto de procedimientos, recursos y medios puestos en práctica para obtener un resultado determinado" (Ariño \& Guinot., 2008) las mismas que se mencionarán y que se consideraron las más eficaces para realizar este estudio.

Es así que las principales técnicas usadas en esta investigación son: La observación la misma que según Gallo \& Guinot (2008) es una técnica básica de todo proceso de investigación y consiste en observar las situaciones o contextos, para obtener información y registrarla para su posterior análisis. Esta información puede ser planificada e intencional con el objetivo de obtenerla de forma un poco más clara y precisa. (Gallo \& Guinot, 2008) 
La observación es utilizada comúnmente para obtener información previa al diálogo al que se debe llegar con el paciente para así notar cierto comportamiento o actitudes que nos puedan dar un indicio sobre el estado de salud, emocional o actitudinal del paciente, y que a primera vista podamos identificar aspectos y rasgos de su entorno más próximo que nos permita enlazar la información que nos brinde con la primera entrevista que se mantenga.

La segunda técnica más importante es la entrevista de la cual Ariño \& Guinot (2008) consideran que “... es un diálogo constructivo guiado por objetivos, siempre revisables a lo largo de todo un proceso reflexivo y sobre todo participativo. Un constructo comunicativo y no un simple registro de discursos que hablan al sujeto o del sujeto...” (Ariño \& Guinot, 2008)

Esta técnica permite al profesional entablar mayor acercamiento a los pacientes además de que facilita los elementos necesarios para una mejor interpretación sobre el contexto en el que va a intervenir. En la misma existen dos momentos o dos tipos de entrevista que se deben llevar a cabo, la primera entrevista se refiere al primer acercamiento que se mantiene con el paciente en esta es importante crear un clima de confianza y de seguridad para que la persona sienta desde el principio que puede confiar en el profesional, a través de los mismo se logra que el paciente proporcione la información pertinente y verdadera para su proceso de atención, en la entrevista subsecuente la persona llega con más confianza y predispuesto a colaborar y corroborar la información que brindo en la primera entrevista o añadir información que omitió o que pudo creer que no es necesaria per que puede ser trascendente para tomarse en cuenta para su tratamiento.

Con las dos técnicas aplicadas en conjunto se lleva a cabo la identificación de comportamientos y relacionados, se brinda un análisis a lo que persona está percibiendo acerca de su condición de salud.

\section{RESULTADOS}

El Trabajo Social se desenvuelve en distintas áreas o campos ocupacionales, desde las cuales debe mantener una perspectiva dependiendo de la población que atiende, en este caso se ve inmerso en el ámbito de la salud donde se mira tanto a la salud como a la enfermedad como procesos históricos y sociales, que se generan en la sociedad de una forma colectiva que nacen desde una mirada social y biológica, y que la misma abarca no solo a las ciencias sociales si no que se ve envuelta e involucrada en las ciencias médicas, pues para ofrecer una atención de tipo integral necesita combinar a las ciencias sociales en procesos llevados a cabo en temas de salud, procesos que tengan que ver con la promoción, prevención, rehabilitación y atención a la población.

Es así que el Trabajo Social ejerce un papel trascendental en su actuar profesional con respecto a las personas con VIH, pues arroja un diagnóstico psicosocial del paciente, esto es parte fundamental del 
diagnóstico general que requiere la persona y la valoración de su estado de salud, de exámenes y consultas médicas a las que está sujeto por su condición, esto indispensable para determinar una atención completa y oportuna que envuelva el entorno completo de la persona VIH positivo, planteando objetivos a alcanzar en relación con el régimen del tratamiento a seguir, el mismo que se determinaría dentro del equipo interdisciplinario, posterior al estudio del caso que se presente.

El Trabajo Social como parte fundamental de un equipo interdisciplinario, contribuye con un diagnóstico social, que aporte con la identificación de factores de riesgo social presentes y a los que está expuesta la persona con VIH, pues estos se ven evidenciados en el círculo, individual, familiar y hasta comunitario, los mismos deben ser vistos del aspectos como el sexo, edad, condición socioeconómica, características de su vivienda, entre varios más, que brinden información que ayude al equipo a establecer una atención eficaz, y un diagnóstico apegado a la evidencia y que compile gran parte del entorno del paciente.

Una vez establecidas las técnicas e instrumentos necesarios para llevar a cabo este estudio, es necesario considerar datos generales obtenidos en el centro médico público en el que se intervino, para determinar la cantidad de personas a las que se atendió y de las cuales cuantas personas arrojaron resultados positivos a la carga viral del virus de inmunodeficiencia humana VIH en su organismo. (Véase tabla 1).

Los profesionales de Trabajo Social son los encargados de analizar la cantidad de personas que acuden cada mes a solicitar las pruebas de VIH y las causas que las llevan a dicho procedimiento, pues muchas de esas personas pueden estar viviendo problemas de salud que se ven relacionados con el VIH, otro porcentaje de pacientes dice haber mantenido relaciones sexuales sin protección con diferentes parejas, otra parte de esta población que recibe dicho servicio son mujeres embarazadas a las que uno de los requisitos para sus controles médicos es realizarse la prueba de VIH para precautelar tanto su salud como la de su bebé.

Tabla 1: Pacientes para consejería previa la prueba de VIH.

\begin{tabular}{|c|c|}
\hline $\begin{array}{l}\text { PACIENTES } \\
\text { CONSEJERIA }\end{array}$ \\
\hline MESES & \# CASOS \\
\hline Abril & 303 \\
\hline Mayo & 161 \\
\hline Junio & 130 \\
\hline Julio & 181 \\
\hline Agosto & 168 \\
\hline TOTAL & 943 \\
\hline
\end{tabular}

Fuente: Departamento de Trabajo Social

Elaborado por: Equipo de Investigación, 2019. 
Producto del estudio realizado, se obtiene que la cantidad más grande de personas que solicitaron la aplicación de la prueba de VIH fue en el mes de abril , 2019, mostrando más afluencia que los otros meses, seguido de los meses de julio, agosto y mayo respectivamente donde la concurrencia de personas no tuvo mayor diferencia entre los tres meses, y por último el porcentaje más bajo se presenta en el mes de junio respecto de las personas atendidas en el periodo comprendido de abril a agosto del año 2019. (Véase gráfico 1)

Gráfico 1. Pacientes atendidos en consejería.

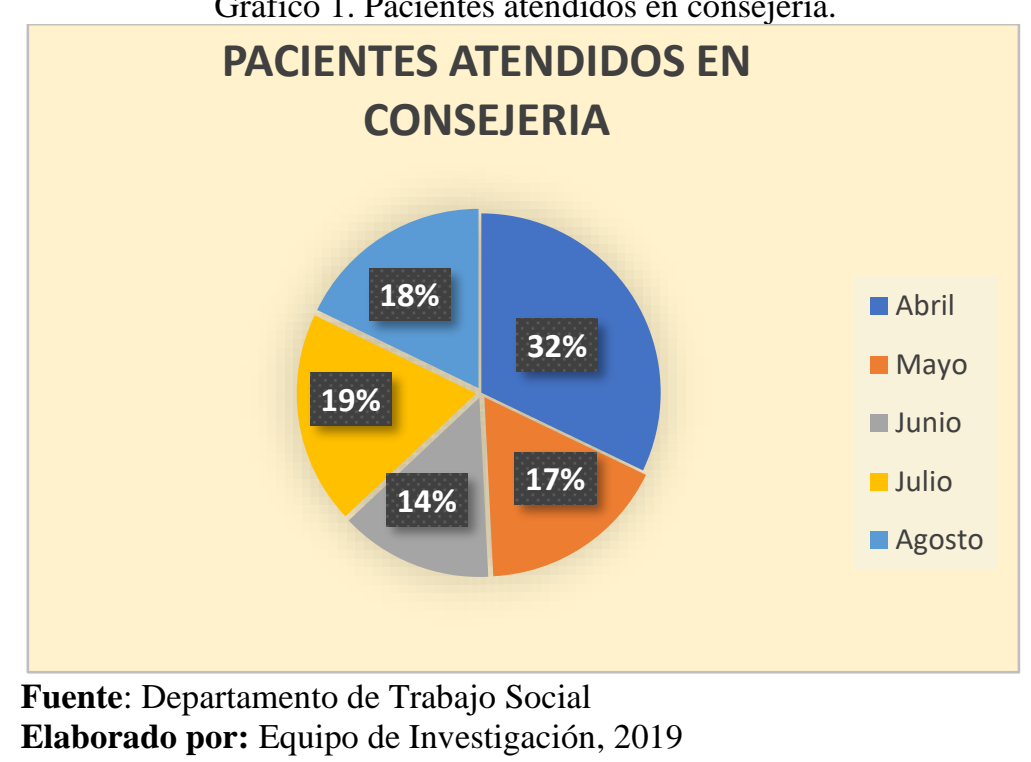

Estos datos respecto a las personas de diversas condiciones (mujeres embarazadas, HSH, etc.) que solicitan llevar a cabo la prueba del VIH, se establecen en los casos que se atienden a las personas que han resultado con VIH positivo. (Véase tabla 2).

Tabla 2: Casos confirmados de VIH en el periodo abril- agosto 2019

\begin{tabular}{|l|l|}
\hline \multicolumn{2}{|c|}{ CASOS POSITTVO } \\
\hline MESES & \#ASOS \\
\hline Abril & 6 \\
\hline Mayo & 14 \\
\hline Jumio & 21 \\
\hline Julio & 23 \\
\hline Agosto & 5 \\
\hline TOTAL & 69 \\
\hline \\
Fuente: Departamento de Trabajo Social \\
Elaborado por: Equipo de Investigación, 2019
\end{tabular}

De la misma forma, la mayor parte de personas que requieren llenar la solicitud de la prueba de VIH (de lo cual se encarga Trabajo Social), son adultos que llevaron a cabo prácticas de sexo, las mismas que eran con personas que acababan de conocer o que mantenían relaciones sexuales con varias parejas con las que no usaban ningún tipo de protección, es aquí donde Trabajo Social interviene, pues se enfoca en recabar todos esos datos y la información necesaria para poder actuar de manera eficiente y posteriormente solicitar los resultados de las pruebas rápidamente. 
A partir de los datos generales mostrados anteriormente, tabla 1, 2 y gráfico 1, se estima un porcentaje por cada mes en el que se fue detectando casos de VIH positivo, por ejemplo se evidencia que en los meses de mayo, junio y julio son los meses que se registran más casos confirmados, y en un porcentaje más bajo son los meses de abril y agosto. (Véase gráfico 2)

Los datos así también muestran que de un total de 943 personas atendidas en el en el Departamento de Trabajo Social del centro médico público, 69 casos resultaron ser casos seropositivos, a los mismos que las Trabajadoras Sociales hicieron un acompañamiento y posterior seguimiento del tratamiento antirretroviral necesario para contrarrestar las afectaciones que tiene la presencia del virus en el organismo, por lo que es necesario desde el momento de conocer el diagnóstico se busque un lugar que disponga de un tratamiento que se ajuste a la realidad del paciente y a su situación de salud, además es importante conocer el compromiso que genere el paciente al cumplimiento de los regímenes del tratamiento y la atención médica que debe llevar.

Gráfico 2: Casos positivos de VIH.

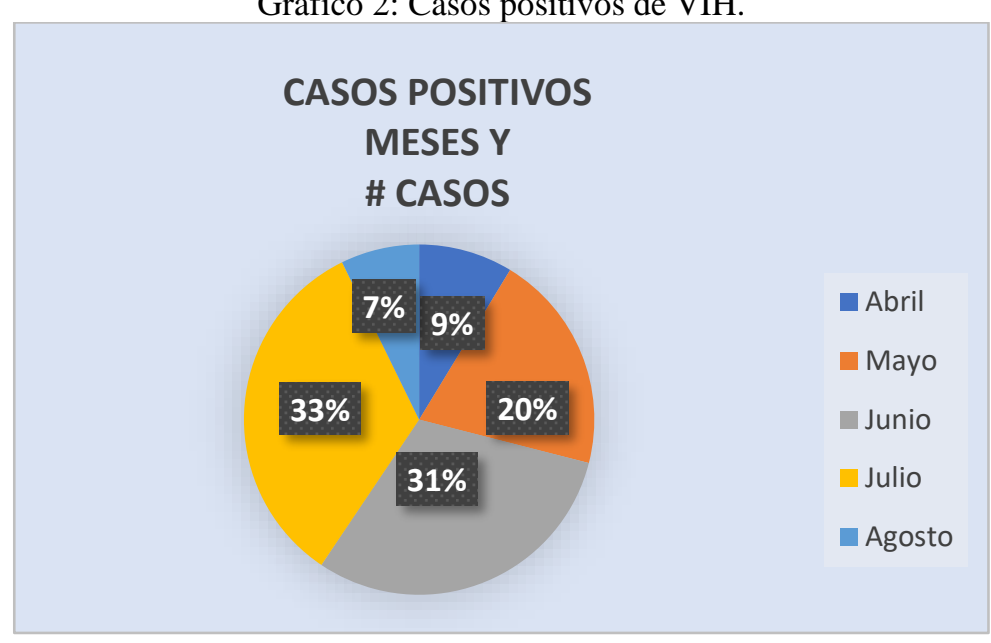

Fuente: Departamento de Trabajo Social

Elaborado por: Equipo de Investigación, 2019

Es precisamente en el área de Trabajo Social, donde se recaban los datos de las personas que necesitan adquirir la solicitud de la aplicación de la prueba del VIH, ya sean estas mujeres embarazadas como requisito médico para el seguimiento de su embarazo, personas que han tenido conductas y prácticas sexuales de riesgo ya sean estas con varias parejas o relaciones sexuales sin protección.

Es oportuno mencionar que cuando el resultado arrojaba un diagnóstico negativo al VIH, es el profesional de Trabajo Social quien se encarga de entregar el resultado; por el contrario si el resultado es positivo es decir la persona resultó con VIH, es el médico general o médico especialista quien se encarga de entregar el diagnóstico y la información médica y oportuna para continuar con el cuidado de la salud del o la paciente, este trabajo hecho conjuntamente con un equipo interdisciplinario en el que Trabajo 
Social interviene como mediador entre el paciente y el lugar médico que posee los tratamientos para que el paciente logre obtener atención para empezar su tratamiento antirretroviral especifico.

La intervención oportuna de Trabajo Social es estratégica, para la ubicación de un lugar adecuado para que el paciente inicie un tratamiento antirretroviral, pues a través de un trabajo focalizado puede orientar a la persona con VIH a que se desenvuelva en una sociedad que por mucho ha mantenido una visión y un criterio equivocados y se ha llenado de estereotipos sobre las personas con VIH como de la enfermedad, formando conceptos que estigmatizan a esta población, como un tipo de construcción cultural que tiende a crear características hacia ciertos grupos, lo que hace que los mismos vean vulnerados sus derechos y consecuentemente envueltos en un círculo total de discriminación.

En virtud de lo anterior el Trabajo Social se plantea como objetivo el trabajo coordinado en el sistema de salud, a fin de garantizar el ejercicio del derecho a la salud, a través de un servicio integrado, y promover el que las personas con VIH reciban el tratamiento necesario, cumpliendo un proceso de atención médico-social que le permita al usuario, llevar un estilo de vida lo más normal posible, reivindicando sus derechos como personas.

\section{DISCUSIÓN}

El VIH,SIDA es una pandemia mundial que ha creado desafíos sin precedentes para los profesionales de la salud, entre los que se ubica el Trabajador Social. Representa una asombrosa crisis de salud pública; el VIH,SIDA también es fundamentalmente un problema de derechos humanos. Muchos factores contribuyen a la propagación de la enfermedad, como la pobreza, la falta de vivienda, el analfabetismo, la prostitución, el tráfico de seres humanos, el estigma y la discriminación y la desigualdad basada en el sexo. Los esfuerzos para vencer a esta enfermedad se ven limitados por la falta de recursos humanos y financieros disponibles en los sistemas de salud (Hirsch, 2003).

El problema del VIH - SIDA es entendido a escala mundial, como una realidad macro social, que además de tener repercusiones epidemiológicas, políticas, económicas, tienen también consecuencias de tipo social, que transforman la vida de la personas que lo padecen, así como de sus entornos más cercanos: los familiares. De ahí que, para intervenir en el mismo, es necesario contar con una visión multidisciplinaria, holística, humanista, de derechos.

Aunque la evolución de la sociedad, ha evidenciado ciertos avances tecnológicos y de información, la sociedad mantiene aún estereotipos marcados sobre la enfermedad. La elaboración de argumentos estigmatizadores es un fenómeno universal, ya que suponen una construcción cultural de las sociedades en torno a las suposiciones creadas hacia los grupos que conviven en una misma sociedad (Huici, 1996), girando su contenido hacia los aspectos particulares de un grupo. La construcción de un estigma, por lo 
tanto, se realiza para contraponer la existencia de un grupo ajeno al considerado como verdadero. De esta manera, se hace alusión a elementos distintivos propios del grupo en cuestión, utilizándolos "para hacer referencia a un atributo profundamente desacreditador" (Goffman, 1989: 13) como se citó en (Capella Castillo et al., 2018, p. 2).

En palabras de Lindsay (1999), La diversidad y la complejidad de los problemas sociales demandan cada día más la experticia de diferentes profesiones de la salud y de lo social. El Trabajo Social es la profesión que más está presente en la composición de equipos multidisciplinarios cuando se trata de intervenciones en problemáticas humanas. Como se citó en (Labra, 2011, p. 8).

De la misma forma, desde su opinión, Dumont (1996) considera que la realidad de la interdisciplinariedad pareciera existir en todos los dominios de intervención en Trabajo Social. El aporte del Trabajo Social en equipos de trabajo multidisciplinarios ha progresado de forma constante en el tiempo. Como se citó en (Labra, 2011, p. 9).

Es evidente que, la discriminación ocurrida a partir del VIH se produce desde diferentes contextos como el familiar y el comunitario, además de influir en las instituciones educativas, servicios de salud, etc. (Sosa, 2011). Numerosas investigaciones indican que las personas afectadas por el VIH, procuran evitar la realidad referente a la infección, hecho que les hace proclives a sufrir distrés emocional y malestar psicológico (Carrobles et al., 2003, p. 6).

En este contexto, los,as Trabajadores,as Sociales en el ámbito de la Salud y particularmente en la atención con pacientes con VIH-SIDA, cumplen funciones trascendentales, pues la experiencia con personas seropositivas amplía la intervención y genera un mayor grado de compromiso al mismo tiempo hace que los procesos emocionales de las profesionales así como de sus actitudes se traduzcan en un sentimiento de satisfacción de su desempeño profesional, así como en atención de calidad a los y las usuarios del servicio público de salud, esto se logra a través del compromiso que sienten las Trabajadoras Sociales respecto a la atención a este grupo, parte de esto también está influido por el nivel de conocimiento que tiene de la enfermedad en su conjunto, y el desprendimiento de prejuicios sociales, asociados a factores socioeconómicos, de edad, sexo, y demás características que determinan la realidad tanto del paciente como del profesional que lo tiende.

Así mismo, la intervención de Trabajo Social, está basada en la defensa de los derechos humanos con los que cuenta cada persona, sin tomar en cuenta ningún tipo de excepción, cada persona tiene y está en la obligación de exigir que sus derechos sean garantizados, en este caso principalmente el acceso a la salud y la vida digna, a la obtención de una terapia antirretroviral y tratamiento integral que le provea de medicamentos que le aseguren una vida digna y su esperanza de vida no se vea afectada a corto plazo. El enfoque de derechos es importante para la intervención de Trabajo Social, pues este cumple con 
el sentido de responsabilidad social, que consiste en la eliminación de las formas de discriminación hacia las personas que viven con VIH y la integración que estos deben tener dentro de la sociedad, esto lleva evidentemente a la inclusión y la generación de redes y lazos sociales necesarios para una mejor convivencia entre los distintos grupos poblacionales y diversidades que existen.

En esta perspectiva de análisis, es importante destacar lo que el Alto Comisionado de las Naciones Unidas plantea con respecto al derecho que tienen las personas con VIH - SIDA, de recibir información:

Las personas que viven con el VIH y los miembros de grupos vulnerables deberían tener apoyo para acceder a información sobre sus derechos, así como herramientas y servicios (p.ej., asistencia jurídica) que les ayuden a reclamarlos. Las instituciones nacionales pueden estudiar la adopción de las siguientes medidas al diseñar programas de información y educación relativos al VIH:

- Contactar con redes de personas que viven con el VIH y organizaciones de la sociedad civil para saber más acerca de sus actividades y necesidades, y proporcionarles apoyo para permitirles divulgar información y formación sobre los derechos de sus miembros y sobre cómo pueden ayudar a las personas a reclamar sus derechos con la asistencia de las instituciones nacionales de derechos humanos.

- Integrar en sus actividades divulgativas información sobre los derechos de las personas que viven con el VIH y los miembros de otros grupos vulnerables.

- Trabajar a través de la autoridad nacional de coordinación del sida y apoyar otras iniciativas dirigidas a proporcionar formación e información sobre los derechos humanos a las personas que viven con el VIH y los miembros de grupos vulnerables. Propugnar y apoyar la creación de servicios gratuitos de asistencia jurídica para las personas que viven con el VIH y los miembros de otros grupos vulnerables (ONUSIDA y ACNUDH, 2007, p. 27)

Por estas consideraciones, el Trabajo Social debe direccionar su intervención, a liderar procesos en los que las personas se vean involucradas, sin distinción de su esfera social, a crear espacios a través de una capacitación adecuada de las profesionales y la actualización de conocimientos, para que sus respuestas y acciones sean cada vez más eficientes y den mejores y más rápidas soluciones a los conflictos que se presenten en el quehacer diario, pues como dice Labra (2011), los y las Trabajadores Sociales desempeñan un papel importante dentro de la intervención en personas con VIH, la misma que con el paso del tiempo los enfrenta con sus propios valores y prejuicios, pues para un mejor entendimiento de dicha intervención es necesario mencionar que el VIH constituye un problema social por lo que se considera un espacio propicio para las acciones que desde Trabajo Social se puedan implementar, y en este sentido importante también acotar que Rutfuts, 1980 considera que "el Trabajo Social es una disciplina práctica que tiene por objeto los problemas sociales de individuos, grupos y colectividades, en una perspectiva de 
intervención colectiva o individual basada en el cambio social" Citado en Labra, (2011), es decir, que los problemas sociales en los que se ve envuelto el ser humano es considerado uno de los principales objetivos del accionar de Trabajo Social en pro de lograr un cambio utilizando al mismo tiempo un análisis y visión crítica de la realidad.

En el Área de Trabajo Social se mantiene continuamente un aprendizaje respecto a la forma de relacionarse con los pacientes y las distintas formas de mantener un diálogo con los grupos poblacionales, ya que cada uno de ellos ya sea de forma individual o colectiva, presentan una variedad de interacciones que definen la manera en la que él o la profesional debe intervenir, lo mismo que constituye un aporte a un cambio de situación y recuperación de los espacios para la profesión, y que desde lo académico, se vayan creando más formas tanto de aprendizaje como de generación de nuevos espacios de intervención para el Trabajo Social en el ámbito social, es por esto que en razón del compromiso académico-profesional y de vida, se debe tener un direccionamiento natural de observación y análisis crítico de la realidad, en la que la persona es vista desde una óptica o como parte de un todo, de un entorno ya sea familiar, social, laboral: por lo que se considera importante la intervención con la población parte de este estudio, y así también la trascendencia que tiene la profesión de afirmar su presencia y contribución con su responsabilidad en el abordaje desde la multidisciplinariedad.

En este orden de análisis, efectivamente se observaron las primeras impresiones del paciente al enterarse de que su examen de VIH salió positivo, el papel que cumple la Trabajadora Social en el equipo médico es indispensable.

Desde esta perspectiva se trabajó en el primer nivel que es el acompañamiento a la persona o paciente en cuestión y analizar su situación y la manera en la que pudo llegar a contraer el virus, para luego indagar sobre su relacionamiento con las personas que puedan verse como posibles portadores del virus y se pueda cortar una cadena de infección que puede ir creciendo, aquí el primer acercamiento supone el punto principal para una correcta intervención, pues se crea un ambiente de confianza con la persona que solicita la aplicación de la prueba, en este punto la Trabajadora Social se vuelve un ente de consulta pues debe despejar y aclarar las dudas y creencias que el usuario pueda tener acerca de la enfermedad, la aplicación de la prueba y su proceso. Cuando los resultados son desfavorables para el paciente es decir es VIH positivo, la Trabajadora Social se convierte en una persona de apoyo y de compañía hasta cierto punto consejera y terapeuta psicológica pues debe atender a los primeros sentimientos y reacciones que la persona presenta, se vuelve un acompañante social y psicológico con la persona enferma y en ocasiones con la pareja de la misma.

Es en estos procesos de atención en Salud que Trabajo Social, se constituye en un ente regulador entre la atención con calidad, el acceso a un tratamiento antirretroviral y el pleno ejercicio del derecho a 
la atención en un sistema de salud y el acceso al mismo que la persona posee, y a la atención integral que esto conlleva, pues aquí se ve reflejado el trabajo interdisciplinario, como un aspecto fundamental para que el paciente continúe con el tratamiento en pro de su bienestar tanto físico como emocional, ya que esta población constantemente se ve afectada por estereotipos y discriminación por parte de su círculo y los ámbitos en los que habita continuamente, al ser una población considerada vulnerable el Trabajo Social debe desarrollar la capacidad de hacer que las prácticas de discriminación sean cada vez menores y que la población se desligue de creencias equivocadas acerca de la enfermedad y el contacto con las personas que la poseen, conforme señala Carballeda (2013) la infección por VIH como una causa para la integración de angustias, ansiedades, miedos, prejuicios y ciertos conceptos que de principio afectaron al carácter moral del problema y su presencia en los actuales discursos sociales. (Carballeda, 2013), partiendo de esto la enfermedad se vuelve un problema social que hace que se refuercen las clasificaciones y el señalamiento a determinados grupos sociales, lo que supone el surgimiento de estigmas y estereotipos que se van extendiendo dentro de la población.

El accionar del Trabajo Social con personas de VIH positivo, ha identificado las necesidades y problemas que se pueden causar al ser diagnosticadas con dicha enfermedad, el papel que juega el profesional parte desde que el paciente llega buscando atención de Salud, es desde ahí que se debe generar un ambiente óptimo para que la persona cualquiera que sea su diagnóstico al final de la aplicación de la prueba de VIH, sienta que tiene un respaldo tanto emocional como profesional que le anime a ser capaz de llevar con conciencia su nueva realidad ya que al ser diagnosticada con VIH positivo se debe someter a constantes controles médicos, psicológicos que comprenden el conjunto de requisitos para seguir con el tratamiento.

Según "Vivir con VIH" un proyecto transnacional desarrollado en varios países de la región como Ecuador, México, Perú, Bolivia, Guatemala y Costa Rica existen razones que impiden que las personas accedan a un tratamiento antirretroviral (ARV), pues la situación actual por la COVID-19 ha provocado que los gobiernos implementen políticas públicas que han hecho que acuerdos internacionales que nacieron para combatir el Virus de Inmunodeficiencia Humana (VIH) se vulneren, por lo tanto violan el reconocimiento al derecho a la salud y a la vida de las personas, los gobiernos ven como una prioridad el combate a la covid-19, es decir, que han cambiado de prioridad, pues las unidades de virología han tenido que centrarse en la atención a pacientes con coronavirus que a los portadores de VIH añadido a esto, es que los paquetes de ARV han reducido la cantidad de medicamentos lo que causa que las personas que lo requieren tengan que visitar los centros médicos de manera más frecuente, en los que muchas veces se evidencia desabastecimiento, otra de las consecuencias de esto es el crecimiento del llamado mercado negro, en el que se trafican con medicamentos de alta demanda para venderlos a precios muy altos, pero 
que tienen la confianza de que las personas que los necesitan los comprarán para no descuidar su tratamiento, que en este caso es el único que le genera un prolongamiento de vida al portar VIH. (León, 2020)

La salud y la vida de las personas con VIH en Latinoamérica depende principalmente de la compra pública de los medicamentos antirretrovirales (ARV), que hagan las entidades competentes por lo que es crucial que estas compras se las realice de forma eficiente, buscando medicamentos de calidad y tomando en cuenta que se debe adquirir la cantidad suficiente para abastecer a todas las personas que los demandan, de estas acciones depende el poder garantizar el derecho que tienen las personas con VIH a la salud y a la vida. Se cree que con la cobertura pertinente y la aplicación y creación de políticas preventivas se podrá cumplir con el objetivo 90-90-90 esta consiste en que "el 90\% de personas con VIH conozcan su estado serológico respecto al VIH, el $90 \%$ de las personas diagnosticadas con el VIH reciban terapia antirretrovírica continuada, y el $90 \%$ de las personas que reciben terapia antirretrovírica tengan supresión viral”, este objetivo fue propuesto para el año 2020 por ONUSIDA. (León, 2020)

Las cifras de casos de seropositivos en la región siguen siendo muy altos pues el VIH se trata también de una pandemia, y que sigue considerándose como una de las más grandes o principales problemas de salud pública, según datos de ONUSIDA (2019) en Ecuador hasta el año 2019 se registraban 43.887 casos de personas seropositivas. Citado en León, (2020). Siendo en 1984 año en el que se registró el primer caso de VIH SIDA en el país, y es desde el mismo que las acciones que se han tomado no han sido eficientes y mucho menos suficientes para ofrecer una atención integral poniendose en evidencia la poca importancia que el sistema de salud le ha dado a esta enfermedad y aun más a las personas que la padecen, poca voluntad política y presupuestos muy bajos para la adquisición de medicamentos esto según, (Coalición ecuatoriana de personas que viven con VIH/SIDA (CEPVVS), 2006), estas mismas respuestas que en la actualidad siguen siendo mínimas y desarticuladas lo que se traduce en la imposibilidad de poder evitar el incremento del VIH en la población.

En nuestro país el conseguir los medicamentos antirretrovirales solo puede ser en hospitales públicos, que hace que las personas que se encuentran lejos de uno o exista un desabastecimiento en el que comúnmente suele conseguir su medicación, sean obligadas a hacer viajes hacia otro hospital, las principales ciudades a las que estos se movilizan son Quito, Guayaquil y Cuenca, en estas son donde se atienden la mayoría de los casos.

En un reportaje hecho por Ana Cristina Basantes (2020), colaboradora del proyecto Vivir con VIH Ecuador, la autora sostiene que, las personas que cuentan con un trabajo formal en el país están afiliadas al Instituto Ecuatoriano de Seguridad Social (IESS), entidad responsable de la seguridad social universal de estas personas, en este servicio está el proveer de antirretrovirales a las personas que viven con VIH 
aunque esto no siempre se cumple por el desabastecimiento que existe. De los 43.887 casos de personas que viven con VIH, el 24\% de estos reciben atención en hospitales que están dentro de la red del IESS, el $75 \%$ en centros de salud pública y el $1 \%$ reciben su tratamiento en la seguridad social de la Fuerzas Armadas y la Policía Nacional. (León, 2020)

Con la atención a los pacientes, Trabajo Social brinda un servicio oportuno a los mismos, a través de las consejerías, la solicitud para la aplicación de la prueba de VIH y las gestiones y acompañamiento que se hace a los pacientes seropositivos para el acceso a un tratamiento antirretroviral, y a los mismos realizar el seguimiento del proceso que llevan desde que se enteran de sus resultados y el momento en el que pueden acceder a una atención integral de su nueva condición, para esto es importante tener datos e información completa acerca de las condiciones socioeconómicas y culturales a las que la persona está expuesta constantemente para de esta manera poder diferenciar los casos y darles como ya lo mencione, un seguimiento dependiendo del caso y sus características particulares dentro del sistema de salud, con el apoyo e intervención de un equipo multidisciplinario que le permita la toma de decisiones y el análisis de las condiciones que la persona presenta para poder arrojar un correcto método, tanto de seguimiento como de atención integral para la enfermedad.

Las personas que viven con VIH, no son personas que suponen un peligro o riesgo latente en la sociedad, pues al ser el VIH una enfermedad tratable que mientras es diagnosticada a tiempo se vuelve indetectable y puede la persona vivir de manera normal siempre y cuando esta cumpla estrictamente con su tratamiento, pues las mismas llevan un proceso de resiliencia y de toma de decisiones para combatir la enfermedad y comprometerse con los cuidados que requieren, muchas de estas personas sienten que con el paso del tiempo su voluntad y su fuerza por defender sus derechos y exigirlos ayuda a abrirse paso en la sociedad y a sentirse incluidos en la misma que por mucho tiempo ha hecho que este grupo viva a la sombra de números y estadísticas anónimas y sin importancia tal vez dentro del sistema principalmente de salud pública.

En definitiva, el trabajo multidisciplinario y activo de Trabajo Social con respecto a este grupo (PVVIH SIDA) puede significar un punto de partida a un espacio aún más amplio y que con el tiempo trascienda a la elaboración de políticas públicas a favor y tomando en cuenta a estas personas y a que se logre y facilite un envejecimiento paulatino de las mismas, en este punto los Trabajadores Sociales deben generar iniciativas en las investigaciones que apunten a esta enfermedad y al contexto de esta, así como contribuir o aportar al mejoramiento de la prácticas y de la intervención, logrando la generación de redes estratégicas en las investigaciones y enlazándolos con otros servicios, instituciones ya sean estas nacionales o de otros países, que busquen incidir en temas de intereses colectivo como lo es el VIH. 


\section{CONCLUSIONES}

- El VIH es un problema de salud pública que ha supuesto un problema de la mayoría sino de todos los países. En el Ecuador, se constituye en un problema tanto social como de salud, pues existe un porcentaje considerable de personas que viven con $\mathrm{VIH}$, considerando que de ese grupo solo existe un estimado ya que podría mencionar que existe probablemente un porcentaje que no sabe que viven con este virus, lamentablemente este grupo poblacional no cuenta con las garantías del ejercicio de su derecho a recibir una terapia oportuna por la falta de tratamientos antirretrovirales y la escasez de los medicamentos en el sistema de salud.

- Esta enfermedad es considerada un problema social colectivo, en el que Trabajo Social se ha mantenido activo con su intervención como integrante del equipo de profesionales en el área de salud, con una intervención individual, y en muchas ocasiones grupal, dependiendo del caso que se presente, pues tanto la profesión como sus profesionales se han mostrado interesados por los grupos y la diversidad poblacional, como ejemplo, el trabajo con personas que han contraído VIH y la importancia de obtener un tratamiento que le permita llevar una vida relativamente normal.

- En la unidad médica pública en Ecuador, se evidenció la importancia que tienen que las personas portadoras de VIH SIDA decidan de forma voluntaria y resiliente dejar a un lado el ser pacientes convencionales y ejercer el rol de protagonistas al concebir como un desafío el poder aceptarse, quererse, agruparse, y verse vinculados a la sociedad sin miedo y sin ocultarse ni ocultar su estado de salud, pues esto no los hace diferentes o los vuelve un motivo de rechazo, por el contrario el aceptar su nueva condición de vida, les genera la confianza y la fuerza que necesitan para seguir con una vida "normal" a la de los demás que no poseen el virus.

- En la atención a pacientes con VIH - SIDA, es de particular importancia que desde la intervención del Trabajo Social, se promueva el trabajo en red, con las distintas instituciones públicas y privadas, centros educativos, unidades médicas, empresas, sectores barriales y población en general, a fin de que transmitan a la sociedad qué es el VIH,SIDA, sus causas y consecuencias para la humanidad, para que la sociedad tome partido frente a la estigmatización y discriminación sufrida por los afectados. Esta discriminación, que además desemboca en problemas emocionales y de autoestima de impredecibles consecuencias.

- Finalmente, la trascendencia que el Trabajo Social tiene en el ámbito de la salud, en la atención a personas con VIH y la complejidad de su realidad desde una perspectiva social nos compromete como Trabajadores,as Sociales a desarrollar y reinventar nuevos conocimientos y mayores habilidades que se hacen necesarias en la intervención inter y multidisciplinaria, es decir juntando lo social y lo médico, esta diada profesional de carácter sinérgico nos facilitaría un abordaje de los 
temas preventivos en los procesos de tratamiento de las diversas problemáticas en lo que al área de la salud se refiere, y las consecuencias que estas tienen sobre la vida de las personas portadoras de VIH SIDA. 


\section{REFERENCIAS}

Alvarez, J., Camacho, S., \& Hidalgo, G. (s.f.). Universidad Autónoma del Estado de Hidalgo. https:,,www.uaeh.edu.mx,scige,boletin,tlahuelilpan,n3,e2.html

Ariño, M., \& Guinot, C. (2008). Métodos, técnicas y documentos utilizados en Trabajo Social. .

Ávila Cedillo, G. J. (2020). Trabajo social en salud: teoría y praxis innovadora. Revista margen $\mathrm{N}^{\circ}$ 97: https:,,www.margen.org,suscri,margen97,Avila-97.pdf

Barranco, M. (2004). La intervención en Trabajo Social desde la calidad integrada. España.

Barreto Acosta, C., Benavides Erazo, J., Garavito Jiménez, A., \& Gordillo Forero, N. (2003). Metodologías y Métodos de Trabajo Social. Método de caso. http:,,www.ts.ucr.ac.cr,binarios,pela,pl-000348.pdf

Capella Castillo, S., Navarro Pérez, J., \& Fajardo Franch, M. (2018). La estigmatización del VIH,SIDA: La respuesta desde el trabajo social. Revista Internacional de Trabajo Social y Bienestar:

https:,,revistas.um.es,azarbe, article,view,322341,254651

Carballeda, A. J. (2013). La Intervención Social en los escenarios actuales. Una mirada al Contexto y el Lazo Social . margen $\mathrm{N}^{\circ}$ 68: https:,,www.margen.org,suscri,margen68, carballeda.pdf

Carrobles, J. A., Remor, E., \& Rodríguez Alzamora, L. (2003). Afrontamiento, apoyo social percibido y distrés emocional en pacientes con infección por VIH. Psicothema [en linea]. 2003, 15(3), 420-426:

https:,,www.redalyc.org,articulo.oa?id=72715313

Coalición ecuatoriana de personas que viven con VIH,SIDA (CEPVVS). (2006). Panoramica de la situación de las personas que viven con VIH,SIDA en el contexto de la epidemia en el Ecuador.

Gallo, L., \& Guinot, C. (2008). Métodos, técnicas y documentos utilizados en Trabajo Social. Técnicas para la obtención, elaboración y proceso de la información.

Gordillo Forero, N. A. (2007). Metodología, método y propuestas metodológicas en Trabajo Social. Revista Tendencia \& Retos No 12: http:,,www.ts.ucr.ac.cr,binarios,tendencias,rev-co-tendencias-12-08.pdf

Gordillo, N. (2007). Metodologías, método y propuestas metodológicas en Trabajo Social. Tendencia \& Retos $\mathrm{N}^{\circ}$ 12.

Labra, O. (2011). Trabajo Social y VIH-SIDA: análisis de prácticas de intervención. Universidad Laval, Quebec, Canadá: https:,,biblat.unam.mx,hevila,RumbosTS,2011,no6,2.pdf

León, D. d. (2020). Vivir con VIH. México.

Ministerio de Salud Pública. (2002). Reglamento de atención a personas con VIH.

ONUSIDA y ACNUDH. (2007). Manual sobre el VIH y los Derechos Humanos para las Instituciones Nacionales de Derechos Humanos. Publicación de las Naciones Unidas:

https:,,www.ohchr.org,Documents,Publications,HandbookHIV_NHRIs_sp.pdf

Organización Mundial de la Salud. (s.f.). Definición de VIH SIDA. https:,,www.who.int,topics,hiv_aids,es,

Vásconez-Alvarado, L. F., \& Galarza Schoenfeld, A. (2021). Influencia del trabajo social en la actitud de pacientes con VIH atendidos en el Hospital Miguel Hilario Alcivar. Pol. Con. (Edición núm. 56) Vol. 6, No 3: https:,,dialnet.unirioja.es, descarga, articulo,7926926.pdf. 